\title{
Preoperative Multidetector Computed Tomography (MDCT) Using Contrast Media for Suspected Acute Appendicitis in Adults: Value and Accuracy
}

\author{
SAHER E. TAMAN, M.D.* and WAEL H. KAMR, M.D. \\ The Department of Diagnostic and Interventional Radiology, Faculty of Medicine, Mansoura University, Mansoura, Egypt
}

\begin{abstract}
Background: Acute Appendicitis (AA) is considered the commonest cause of acute abdomen in adults. Its clinical presentation is not always clear and only $70 \%$ of patients have the classic signs and symptoms. Quick and safe diagnosis can be acquired in classic cases clinically assisted by laboratory results. Atypical presentation can be up to one third of patients with AA. Other abdominal conditions may also represent as AA especially in women. Also, the diagnostic value of laboratory markers (CRP and WCC) remains a controversial. Missing diagnosis of AA leads to severe complications Ultrasound (US) examination has many limitations in diagnosis of AA. Multi-Detector Computed Tomography (MDCT) is well established for diagnosis of AA with high sensitivity. So, the radiologist can confidently diagnose or exclude AA, its severity and complications to guide appropriate management.
\end{abstract}

Aim of Study: The aim of this study is to assess the diagnostic value and accuracy of pre-operative MDCT in suspected AA in adults.

Patients and Methods: This prospective study included 200 adult patients presented with clinical picture of AA, either typical or atypical. Post intravenous contrast MDCT was performed for all patients. Axial images were reconstructed with coronal and sagittal reformatted images. Then images were evaluated for the presence or absence of AA, associated complications or other pelviabdominal abnormalities.

Results: Two hundred patients (120 females and 80 males with age range between 21-65 years and mean age 35) were having clinical presentation of acute right iliac fossa pain. According to the CT findings 140 patients $(70 \%)$ diagnosed as AA and 60 patients $(30 \%)$ were negative for appendicitis. The CT findings were limited to the appendix only in 75 patients $(37.5 \%)$ and were coping with simple acute appendicitis. A group of 39 patients (19.5\%) diagnosed as AA with peri-appendicular inflammatory changes. CT findings in a small group of patients $(12$ patients $6 \%$ ) showed mixed inflammatory reaction with regional lymphadenopathy and

Correspondence to: Dr. Saher E. Taman, The Department of Diagnostic and Interventional Radiology, Faculty of Medicine, Mansoura University, Mansoura, Egypt minimal free fluid they were diagnosed as AA with phlegmon. CT signs of perforated appendix detected in 10 patients $(5 \%)$. Only 4 patients $(2 \%)$ diagnosed as appendicular mucocele. The other 60 patients $(30 \%)$ were negative for appendicitis. 20 patients $(10 \%)$ showed right ovarian cysts, 10 patients $(5 \%)$ had right ureteric stones, 5 patients $(2.5 \%)$ had epiploic appendagitis and 25 patients $(12.5 \%)$ negative for any pathology. All cases with positive CT findings subjected to surgery and the operative findings were matching with the CT findings.

Conclusion: MDCT is an accurate, effective technique for diagnosing acute appendicitis. It also affects surgical management plan. In addition, it avoids unnecessary operation.

Key Words: Acute appendicitis - MSCT-Acute abdomen.

\section{Introduction}

ACUTE Appendicitis (AA) is considered the commonest cause of acute abdomen in adults [1]. The clinical presentation of AA not always clear. Only $70 \%$ of patients have the classic signs and symptoms which are: Periumbilical pain migrating to the right lower quadrant, nausea, anorexia, fever and guarding at McBurney's point [2].

Quick and safe diagnosis can be easily acquired in the classic cases by clinical history and physical examination assisted by laboratory results as elevated C-Reactive Protein (CRP) and White Cell Count (WCC). If one of these classic findings is missing, it is called atypical presentation of AA which can be up to one third of the patients with AA $[2,3]$.

Other patients with alternative abdominal conditions may represent with clinical findings which could not be differentiated from acute appendicitis $[4,5]$. Based on clinical diagnosis of AA, many patients were found to have normal appendix at 
surgery in about $8-30 \%$ [6,7]. This percent was found to be increased in women up to $40 \%$ due to gynecologic disease which can confound the diagnosis of AA. Also, the diagnostic value of CRP and WCC remains a controversial issue as recent studies showed low diagnostic accuracy in AA for these markers [8].

Missing diagnosis of AA leading to severe complications with increased morbidity and mortality if appendicular perforation occurs $[9,10]$ Using modern diagnostic methods to exclude or confirm AA proved to be helpful to decrease unnecessary negative appendectomy $[11,12]$.

Ultrasound (US) examination was used in diagnosis of AA. It has many advantages but also many limitations are present, the most important of these limitations is that it could not detect normal or perforated appendix and it is operator dependent $[13,14]$. Multi-Detector Computed Tomography (MDCT) is well established for diagnosis of AA in adults with high sensitivity $90-100 \%$. It is considered superior to US because it can detect the appendix, peri appendiceal tissues and other intraabdominal structures [15-17]. So, the radiologist can confidently diagnose or exclude appendicitis, moreover it can detect severity and extensions of the inflammatory process helping to guide appropriate management $[\mathbf{1 7 , 1 8}]$

The aim of this study is to assess the diagnostic value and accuracy of pre-operative MDCT in suspected AA in adults.

\section{Patients and Methods}

\section{Patients:}

This prospective study was done in the period between January 2015 to December 2016, for cases referred from Emergency Department. The study was carried out on 200 patients (80 males, 120 females, age \pm 35 years, rang 21-65 years) presented with clinical picture of AA, either typical or atypical. Subjects were selected according to the following inclusion and exclusion criteria.

\section{Inclusion criteria:}

Referral based on clinical examination with symptoms and signs of AA like:

A- Adult patient with age more than 18 years old.

B- Typical presentation: Symptoms including nausea, vomiting, pain in the right lower quadrant and anorexia while the signs are local tenderness and guarding at McBurney's point, rebound tenderness and fever (more than $37.3^{\circ}$ of the oral temperature). Elevated CRP and WCC.

$C$-Atypical presentation: Absence of at least one of the classic findings of AA.

D- Women with normal gynecologic examination.

E- Patients with available surgical results after appendectomy.

\section{Exclusion criteria:}

Patients with no available post-surgical results, also patients with history of allergy to intravenous contrast media, renal impairment or intravenous line inaccessibility for whom post-contrast study was contraindicated.

\section{Methods:}

Post intravenous contrast MDCT was performed on a multidetector CT scanner (128 row multislice volume scanner Philips Healthcare, Best, Netherlands). Oral CM were given for 165 patients $(82.5 \%)$ for 2 hours prior to CT examination, while the remaining 35 patients $(17.5 \%)$ refused oral contrast due to vomiting. Intravenous contrast administrated on the table, $120 \mathrm{~mL}$ Iopamidol intravenously at a rate of $3 \mathrm{~mL} / \mathrm{sec}$ via the antecubital vein using bolus-triggering technique. Imaging in inspiration starting 60 seconds of initiation of contrast infusion covering the region from the diaphragm to the symphysis pubis. Oral contrast was given to the patients gradually 2 hours before the procedure. Transaxial images were reconstructed with slice thickness of $3 \mathrm{~mm}$. Coronal and sagittal reformatted images were also obtained.

\section{CT findings:}

\section{Normal:}

- The normal appendix appears in CT as a tubular structure in the right iliac fossa region, directed medially and/or inferiorly from the cecum with a length of $3-20 \mathrm{~cm}$, and with a diameter of less than $6 \mathrm{~mm}$ with its lumen shows oral contrast in addition to presence or absence of gas in the lumen. The presence of appendicolith does not confirm or rule out a diagnosis of appendicitis but increase the risk of appendicitis \& its perforation.

- Be aware about the atypical location of the appendix like in case of retro-cecal or sub-hepatic appendix.

- There are primary and secondary findings of appendicitis in CT. Primary findings refer to alterations of the appendix proper. Secondary 
findings correspond to the alteration in adjacent structures by the inflammatory process.

\section{Primary findings:}

- Increase in transverse diameter: There is an increase in transverse diameter when it is greater than $6 \mathrm{~mm}$.

- Thickening of the wall of the appendix greater than $1 \mathrm{~mm}$.

- Abnormal and heterogeneous enhancement of the wall.

- The submucous edema or stratification which configures the "Target" or "Diana" sing.

- Appendicoliths.

\section{Secondary findings:}

- Focal thickening of the walls of the cecum around the insertion of the cecal appendix; because of this, this process forms a "funnel" image which points towards the origin of the appendix and it configures the "arrowhead sign" with enteral contrast.

- On the other hand, the "sign of cecal bar" appears when the thickened wall of the cecum surrounds an enclaved appendicoliths in the root of the appendix.

- The alteration in the density of peri-appendicular fat.

- It is common to find regional lymphadenopathy.

- Signs of perforation: The presence of extra luminal gas, the visualization of an abscess, phlegmon, the presence of an extra-luminal appendicolith or a focal defect in the enhancement of the wall. The co-existence of two of the previously described findings indicates perforation.

The appearance of appendicitis on CT depends on the extent and severity of inflammation, and the presence or absence of complications.

\section{Results}

This study included 200 patients of acute appendicitis referred to the radiology department from Emergency Department, during the period from January 2015 to December 2016, they were 120 female and 80 male with age range between 21-65 years and mean age 35 . All of them had clinical presentation of acute right iliac fossa abdominal pain and referred for multidetector computed tomography evaluation of acute appendicitis.
According to the CT findings 140 patients (70\%) diagnosed as appendicitis and 60 patients (30\%) were negative for appendicitis. The CT findings were limited to the appendix only in 75 patients $(37.5 \%)$ showing distended and increased transverse diameter, thickening and enhancement of its wall, no oral contrast opacification while the surrounding fat plans were clear, appendicolith was detected in 25 patients of them. These findings were coping with simple acute appendicitis.

A group of 39 patients (19.5\%) diagnosed as AA with peri-appendicular inflammatory changes as the CT findings showed involvement of the surrounding fat plans by increased their attenuation and stranding in addition to the previous signs noticed in the first group. CT findings in a small group of patients (12 patients $6 \%$ ) showed mixed inflammatory reaction with soft tissue density like mass at the site of the appendix and associated with surrounding fat stranding, regional lymphadenopathy and minimal free fluid they were diagnosed as AA with phelgmon.

CT signs of perforated appendix detected in 10 patients (5\%); their findings were as follow including:

- Ill definition of the appendix with wall defect and associated with marked inflammatory reaction, extra-luminal air density and free fluid (4 patients)

- Non visualized appendix with appendicular abscess/collection and extra-luminal air density, extra-luminal appendicolith (6 patients).

4 patients (2\%) showed markedly distended appendix with enhancing wall and mild inflammatory reaction around. After reviewing their clinical history, we found that they had recurrent complaint of right iliac fossa pain with no previous imaging or intervention. The CT diagnosis was appendicular mucocele.

The other 60 patients (30\%) were negative for appendicitis; 20 patients (10\%) showed right ovarian cysts, including corpus luteal cyst, 10 patients $(5 \%)$ had right ureteric stones, 5 patients $(2.5 \%)$ had epiploic appendagitis and 25 patients $(12.5 \%)$ negative for any pathology.

All cases with positive CT findings subjected to surgery. The operative findings were matching with the CT findings in all patients in addition to the histopathological correlation with cases diagnosed as appendicular mucocele. 
Table (1): Showing CT findings in (+ve) cases of AA, number and percent.

Table (2): Showing CT findings in (-ve) cases of AA, number and percent.

\begin{tabular}{|c|c|c|c|c|c|}
\hline $\begin{array}{l}\text { CT findings in }(+v e) \\
\text { cases for appendicitis }\end{array}$ & $\begin{array}{l}\text { Number } \\
\text { of cases }\end{array}$ & $\%$ & $\begin{array}{l}\text { CT findings in }(-v e) \\
\text { cases for Appendicitis }\end{array}$ & $\begin{array}{l}\text { Number } \\
\text { of cases }\end{array}$ & $\%$ \\
\hline Simple Acute Appendicitis (AA) & 75 & 37.5 & Right ovarian cysts & 20 & 10 \\
\hline AA with peri-appendicular changes & 39 & 19.5 & Right ureteric stones & 10 & 5 \\
\hline AA with phlegmon & 12 & 6 & Epiploic appendagitis & 5 & 2.5 \\
\hline $\begin{array}{l}\text { Perforated Appendix } \\
\text { Appendicular mucocele }\end{array}$ & $\begin{array}{l}10 \\
4\end{array}$ & $\begin{array}{l}5 \\
2\end{array}$ & Negative for any pathology & 25 & 12.5 \\
\hline Total & 140 & 70 & Total & 60 & 30 \\
\hline
\end{tabular}

\section{Case presentation:}

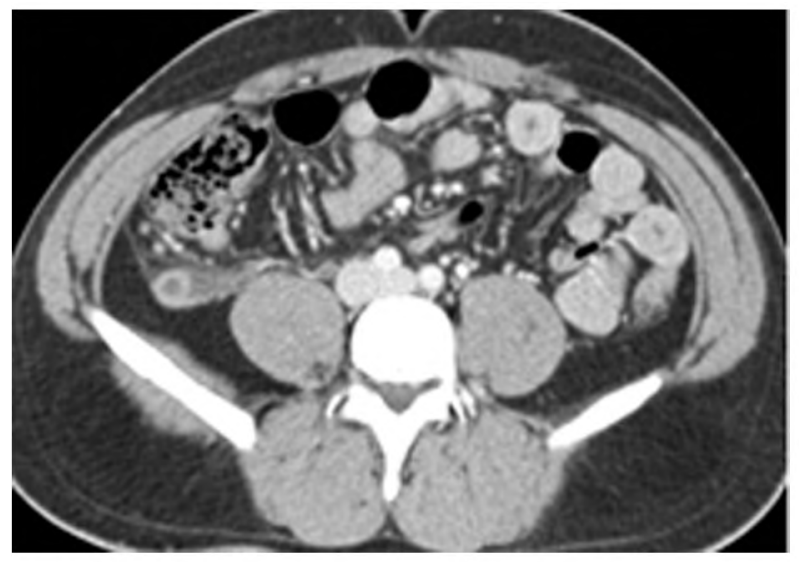

(A)

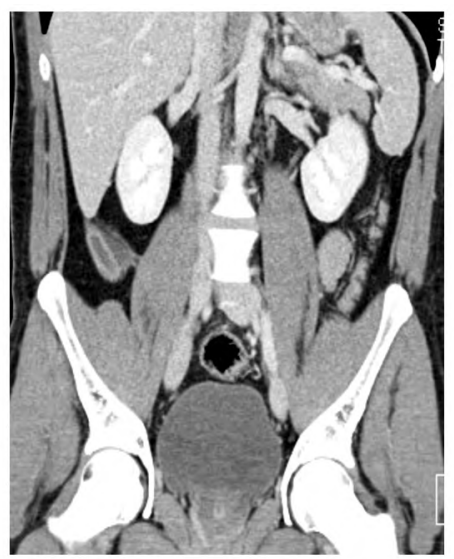

(B)

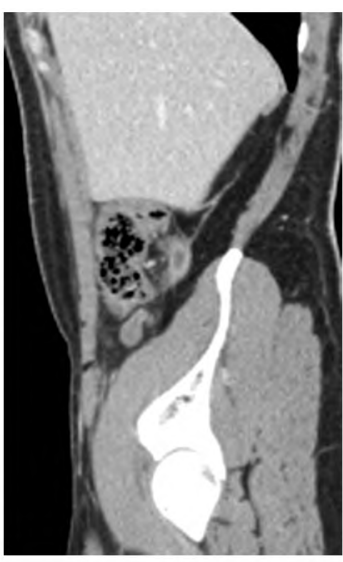

(C)

Fig. (1): Acute appendicitis in 30 years old male patient presented with right lower quadrant acute abdominal pain. Post IV contrast of the abdomen and pelvis Axial (A), Coronal (B) \& Sagittal (C) Showing thickening and enhancement of the wall of the appendix. Its lumen is seen filled with fluid. There is also haziness and streaking of the of the related fat indicating its inflammation.
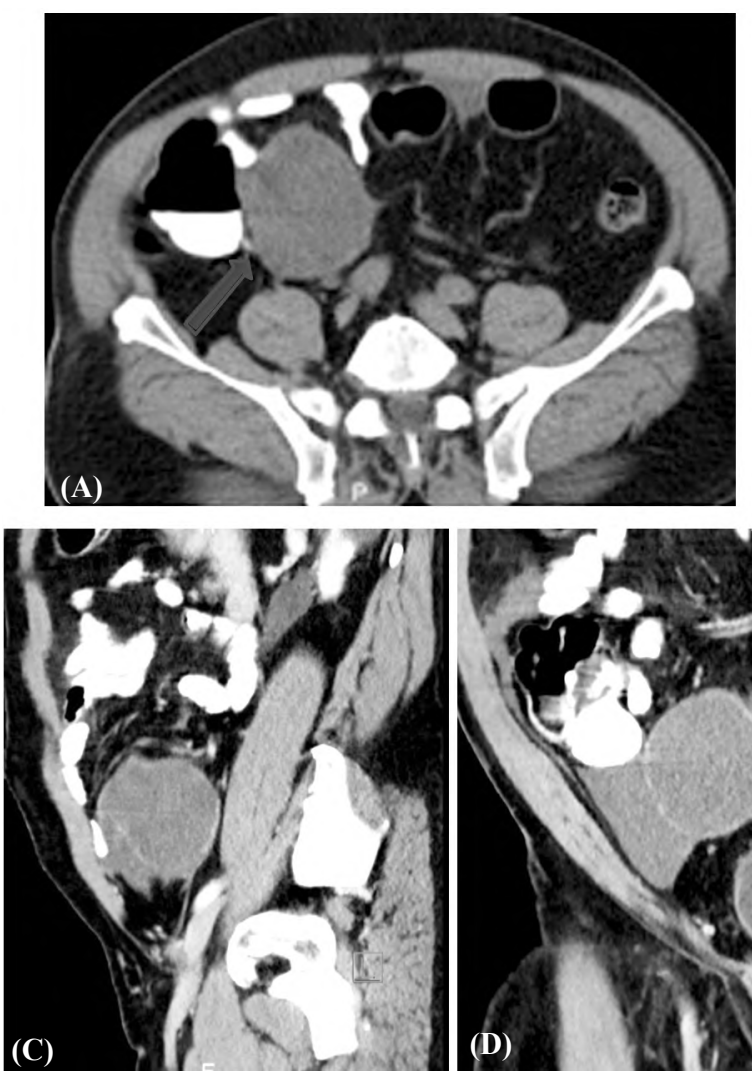

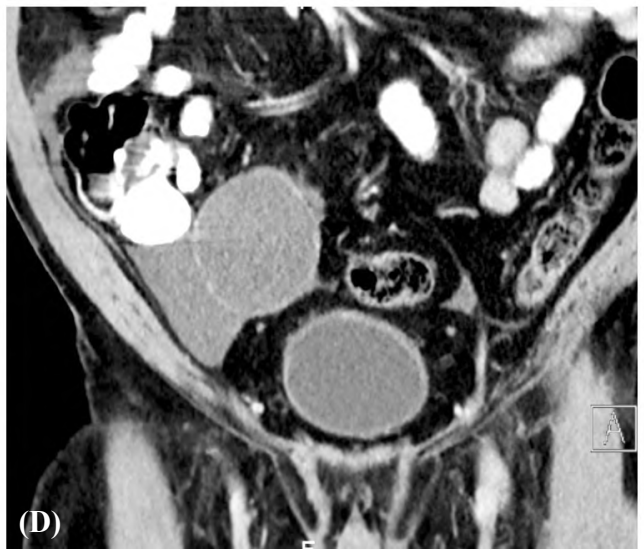

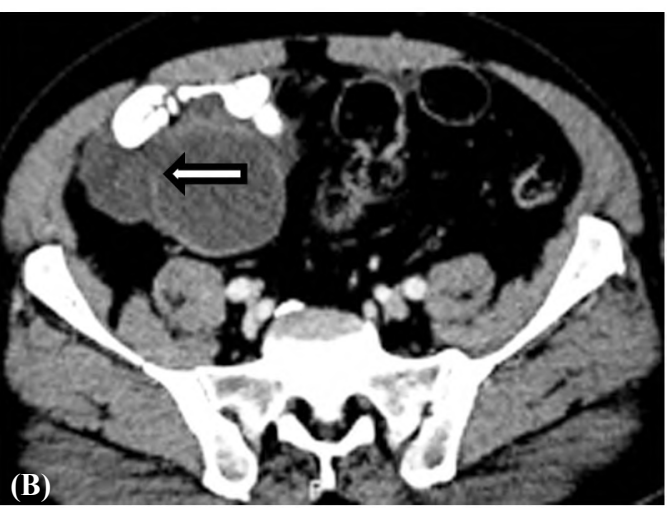

Fig. (2): Appendiceal mucocele with perforation in 36 years old male patient complaining from right lower quadrant acute abdominal pain. (A,B) Axial. (C,D) Sagittal and coronal post oral and IV contrast CT showing thin walled cystic lesion containing fluid beside the cecum and in continuity with the appendix (yellow arrow). There is faint mural enhancement with small defect in the lateral aspect of its wall (white arrow), fluid is seen lateral to it... Indicating perforation. 

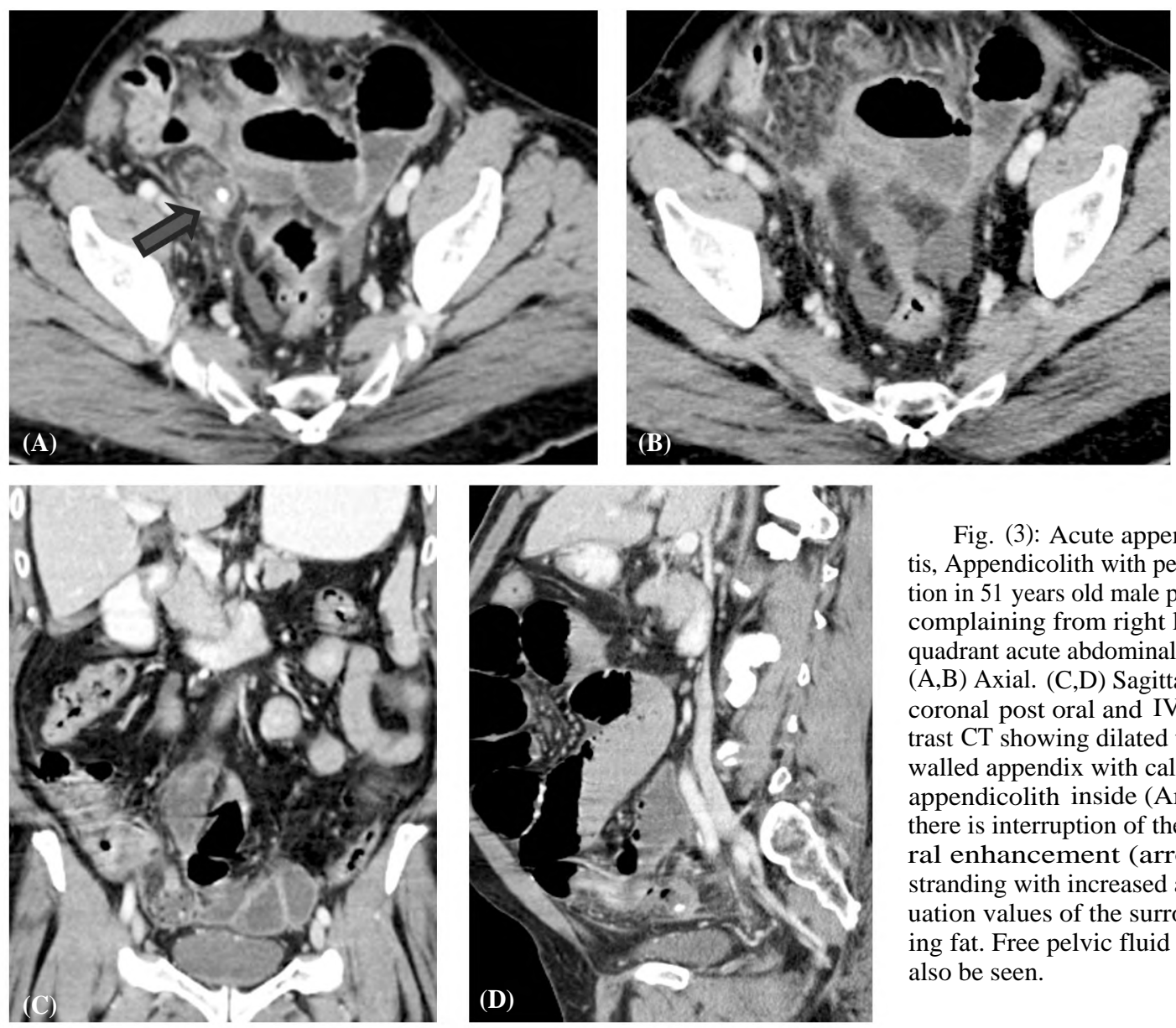

Fig. (3): Acute appendicitis, Appendicolith with perforation in 51 years old male patient complaining from right lower quadrant acute abdominal pain. (A,B) Axial. (C,D) Sagittal and coronal post oral and IV contrast CT showing dilated thickwalled appendix with calcified appendicolith inside (Arrow) there is interruption of the mural enhancement (arrow), stranding with increased attenuation values of the surrounding fat. Free pelvic fluid could also be seen.
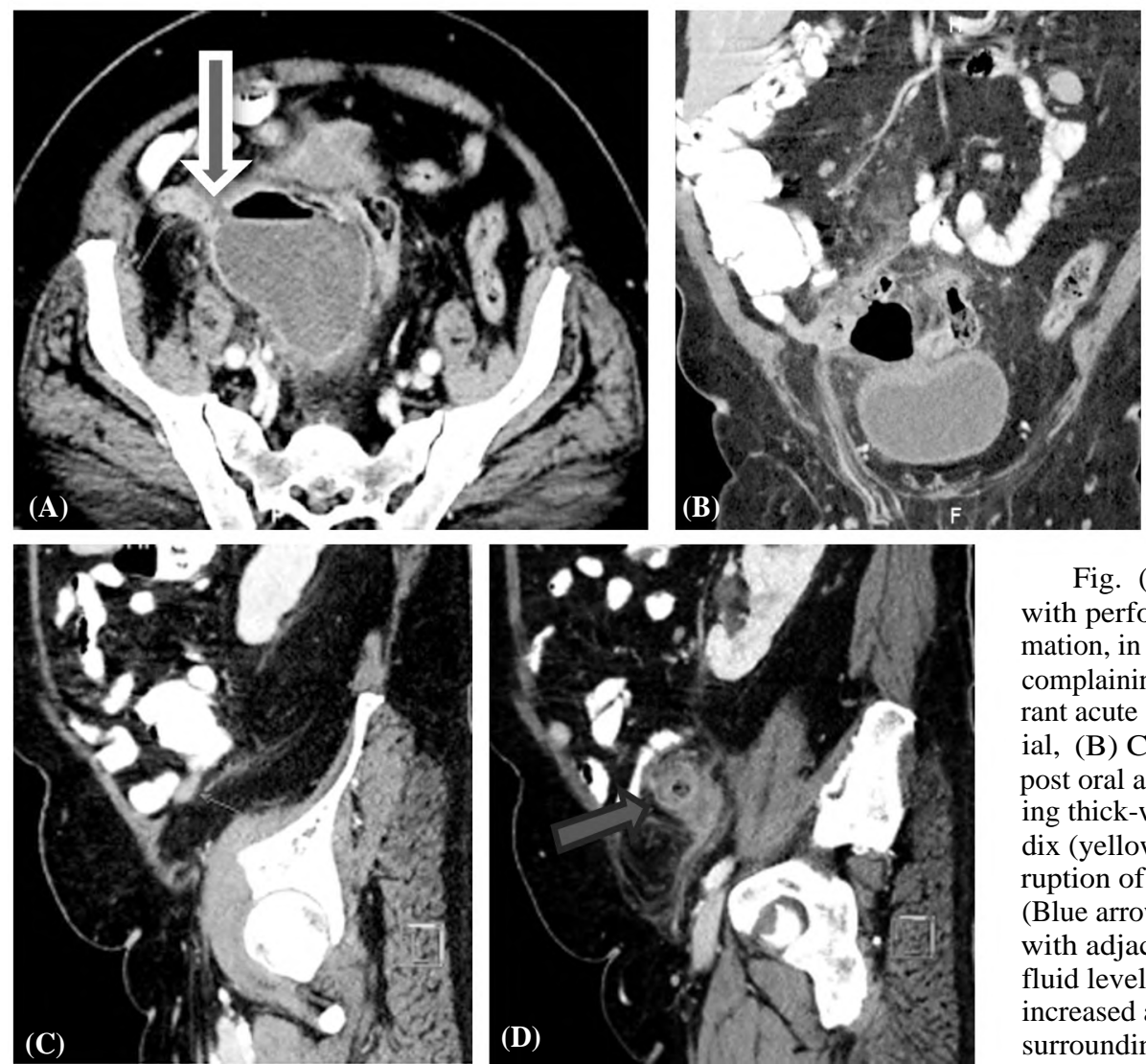

Fig. (4): Acute appendicitis with perforation and abscess formation, in 45 years old male patient complaining from right lower quadrant acute abdominal pain. (A) Axial, (B) Coronal, (C, D) Sagittal post oral and IV contrast CT showing thick-walled enhancing appendix (yellow arrows), there is interruption of the mural enhancement (Blue arrow), then seen connecting with adjacent collection with air/ fluid level. There is stranding with increased attenuation values of the surrounding fat. 


\section{Discussion}

Acute appendicitis is one of the most common surgical abdominal emergencies among general population and although in most cases the diagnosis of acute appendicitis is usually clear on the basis of clinical features, there is a significant negative laparotomy rate reaching up to $30 \%$. Accurate diagnosis is required to reduce the morbidity and mortality of acute appendicitis in addition to the negative cases $[\mathbf{8 , 1 9 ]}$.

The continuous growing up technology of variable medical imaging techniques and machines provides an important role in the diagnosis of AA, especially US and MDCT [20]. Therefore, some authorities now recommend CT for all patients with suspected acute appendicitis or for those with equivocal acute appendicitis. CT may also be helpful in the preoperative evaluation of patients undergoing laparoscopic appendectomy to confirm the diagnosis, detected complication or to reduce the morbidity and mortality of acute appendicitis $[21,22]$.

Due to its high sensitivity and specificity, Computed Tomography (CT) is becoming the preferred imaging modality for suspected acute appendicitis, particularly in adults [8]. CT is more accurate in the diagnosis of acute appendicitis since it is less operator dependent than Ultrasonography (US). CT seems to be more sensitive (96\% Vs. $76 \%$ ) and accurate $(94 \%$ Vs. $91 \%)$ than US in diagnosing acute appendicitis, whereas they are almost equal when it comes to specificity ( $89 \%$ Vs. $91 \%$ ). CT imaging tailored to evaluate acute appendicitis has proven to be particularly successful with a sensitivity of $100 \%$, specificity of $95 \%$, positive predictive value of $97 \%$, negative predictive value of $100 \%$, and accuracy of $98 \%$ [20]. Multidetectorrow CT (MDCT) currently has an important role in the diagnosis of acute appendicitis and its severity. Some authors suggest that they can diagnose acute appendicitis with an accuracy of $99 \%$ [23] It is also possible to reconstruct the entire form and position of appendices from successive CT findings because of high-resolution thin-slice MDCT images [24,25]

In the current study, MSCT showed 60 patients (30\%) had negative result for acute appendicitis with subsequent decrease in the rate of negative appendectomy. In the other positive cases (140 patients $70 \%$ ), the appearance of appendicitis on CT depends on the extent and severity of inflammation, and the presence or absence of complications, so CT classification of appendicitis based on CT findings, acute appendicitis may be classified into 4 categories of increasing severity. In our study and according to this classification, the CT showed:

- Category 1: Simple appendicitis in which findings are limited to the appendix and the lumen of the appendix may be distended with a thick and enhancing wall (75 patients $37.5 \%$ ).

- Category 2: Appendicitis with peri- appendicular inflammatory changes. In this case, the fat surrounding the appendix and/or cecum appears enhanced (39 patients 19.5\%).

- Category 3: Appendicitis with appendicular phlegmon or abscess (12 patients 6\%).

- Category 4: Appendicitis with distal inflammatory changes. This is the most severe type, indicating perforation of the appendix with dissemination of the inflammatory process. (10 patients 5\%).

-While in the last 4 patients (2\%), the CT showed a well-circumscribed, low-attenuation, spherical or tubular mass like contiguous with the base of the cecum and diagnosed as appendicular mucocele with operative and histopathological confirmation.

MSCT gives accurate diagnosis of AA in addition it gives the exact extension of the inflammatory reaction, associated complications like abscess formation, collection or perforation. Signs of perforation can be seen at CT include; ill-definition of the appendix with wall defect, extra-luminal air density, extra-luminal oral contrast leakage, extraluminal appendicolith, phelgmon or abscess, combination of two of them confirm perforation.

On the other hand, MDCT can show the differential diagnosis of AA from other causes of acute abdomen like diverticulitis, ureteric stones, ovarian cysts or epiploic appendagitis, ovarian torsion, abscess, ectopic pregnancy, crohn's disease. In our study we found 60 patients negative for AA including 20 patients $(10 \%)$ with right ovarian cysts, including corpus luteal cyst, 10 patients $(5 \%)$ had right ureteric stones, 5 patients $(2.5 \%)$ had epiploic appendagitis and 25 patients $(12.5 \%)$ negative for any pathology.

One of the major advantages of MDCT is the reconstructed coronal and sagittal reformats in addition to the oblique reconstruction view if needed [25]. These reformatted images provide a great help in localization of the appendix if not easily seen on the axial images, especially if it is sub-hepatic or retro-cecal appendix [26] 
From other point of view, MDCT has some limitations like hazards of exposure to ionizing radiation, possible adverse reactions to IV contrast material and discomfort caused by enteric agents.

\section{Conclusion:}

MDCT is an accurate, effective technique for diagnosing acute appendicitis. Familiarity with CT findings is important for the correct diagnosis of acute appendicitis, differentiation of appendicitis from other entities, and identification of complications. MDCT affects surgical management plan according the severity and complications associated. In addition, it avoids unnecessary operation and decreased rate of negative appendectomy. Our recommendation, every patient with suspected AA should perform MDCT prior to surgery.

\section{References}

1- GAITINI D., BECK-RAZI N., MOR-YOSEF D., et al.: Diagnosing acute appendicitis in adults: Accuracy of color doppler sonography and MDCT compared with surgery and clinical follow-up. AJR. Am. J. Roentgenol., 190: 1300-6, 2008

2- PETROIANU A.: Diagnosis of acute appendicitis. Int. J. Surg., 10: 115-9, 2012.

3- POOLER B.D., LAWRENCE E.M., and PICKHARDT P.J.: MDCT for suspected appendicitis in the elderly: Diagnostic performance and patient outcome. Emerg. Radiol., 19: 27-33, 2012.

4- PETROIANU A. and ALBERTI L.R.: Accuracy of the new radiographic sign of fecal loading in the cecum for differential diagnosis of acute appendicitis in comparison with other inflammatory diseases of right abdomen: A prospective study. J. Med. Life, 5: 85-91, 2012.

5- ESHED I., HALSHTOK O., ERLICH Z., et al.: Differentiation between right tuboovarian abscess and appendicitis using CT A diagnostic challenge. Clin. Radiol., 66: 1030$5,26,2011$.

6- COURSEY C.A., NELSON R.C., PATEL M.B., et al.: Making the diagnosis of acute appendicitis: Do more preoperative CT scans mean fewer negative appendectomies? A 10- year study. Radiology, 254: 460-8, 2010.

7- RAJA A.S., WRIGHT C., SODICKSON A.D., et al.: Negative appendectomy rate in the era of CT: An 18-year perspective. Radiology, 256: 460-5, 2010.

8- CHALAZONITIS A.N., TZOVARA I., SAMMOUTI E., et al.: CT in appendicitis. Diagn. Interv. Radiol., 14: 1925, 2008.

9- SUH S.W., CHOI Y.S., PARK J.M., et al.: Clinical factors for distinguishing perforated from nonperforated appendicitis: A comparison using multidetector computed tomography in 528 laparoscopic appendectomies. Surg. Laparosc. Endosc. Percutan. Tech., 21: 72-5, 2011.

10- PINTO M. PEREIRA1 RUI P., and CLAUDE S.: CT
Evaluation of Appendicitis and Its Complications: Imaging Techniques and Key Diagnostic Findings. AJR, 185: 40617, 2005.

11- ARÉVALO O., MORENO M. and ULlOA L.: Acute appendicitis: Imaging findings and current approach to diagnostic images, Rev. Colomb. Radiol., 25 (1): 3877 88, 2014.

12- NAEGER D.M., CHANG S.D., KOLLI P., et al.: Neutral vs positive oral contrast in diagnosing acute appendicitis with contrast-enhanced CT: Sensitivity, specificity, reader confidence and interpretation time. Br. J. Radiol., 84: 418-26, 35, 2011.

13-REICH B., ZALUT T. and WEINER S.G.: An international evaluation of ultrasound Vs. computed tomography in the diagnosis of appendicitis. Int. J. Emerg. Med., 4: 68, 2011.

14- VAN R.A., BIPAT S., ZWINDERMAN A.H., et al.: Acute appendicitis: Meta-analysis of diagnostic performance of CT and graded compression US related to prevalence of disease. Radiology, 249: 97-106, 2008.

15- KRAJEWSKI S., BROWN J., PHANG P.T., et al.: Impact of computed tomography of the abdomen on clinical outcomes in patients with acute right lower quadrant pain: A meta-analysis. Can. J. Surg., 54: 43-53, 2011.

16- STENGEL J.W., WEBB E.M., PODER L., et al.: Acute appendicitis: Clinical outcome in patients with an initial false-positive CT diagnosis. Radiology, 256: 119-26, 2010.

17- PARKS N.A. and SCHROEPPEL T.J.: Update on imaging for acute appendicitis. Surg. Clin. North Am., 91: 14154, 2011.

18- MORSE B.C., ROETTGER R.H., KALBAUGH C.A., BLACKHURST D.W. and HINES W.B.: Abdominal CT scanning in reproductive-age women with right lower quadrant abdominal pain: Does its use reduce negative appendectomy rate and healthcare costs? Am. Surg., 73: 580-4, 2007.

19- GUSS D.A., BEHLING C.A. and MUNASSI D.: Impact of abdominal computed tomography on the rate of negative appendicitis. J. Emerg. Med., 34: 7-11, 17, 2008.

20- SCHWARTZ D.: Imaging of suspected appendicitis: Appropriateness of various imaging modalities. Pediatr. Ann., 37: 433-8, 2008.

21- KIM K., LEE C.C., SONG K-J., KIM W., SUH G. and SINGER A.J.: The impact of helical computed tomography on the negative appendectomy rate: A multi-center comparison. J. Emerg. Med., 34 : 3-6, 2008.

22- HEKIMOGLU K., YILDIRIM U.M., KARABULUT E., et al.: Comparison of combined oral and I.V. contrastenhanced versus single i.v. contrast-enhanced mdct for the detection of acute appendicitis. JBR-BTR, 94: 27882, 2011.

23- FREI S.P., BOND W.F., BAZURO R.K., RICHARDSON D.M., SIERZEGA G.M. and REED J.F.: Appendicitis outcomes with increasing computed tomographic scanning. Am. J. Emerg. Med., 26: 39-44, 2008. 
24- ANDERSON S.W., SOTO J.A., LUCEY B.C., et al.: Abdominal 64-MDCT for suspected appendicitis: The use of oral and IV contrast material versus IV contrast material only. AJR. Am. J. Roentgenol., 193: 1282-8, 2009.

25- NEVILLE A.M. and PAULSON E.K.: MDCT of acute appendicitis: Value of coronal reformations. Abdom Imaging, 34: 42-48, 2009.

26- ABOUGABAL A.M., AFIFI A.H. and KASEM M.I.: Role of Multidetector Computed Tomography (MDCT) in diagnosis of subhepatic appendicitis. The Egyptian Journal of Radiology and Nuclear Medicine, 43: 347-52, 2012.

\section{التصوير المقطعى متعدد الكواشف بإستخدام مواد التباين

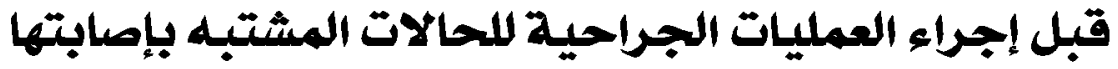

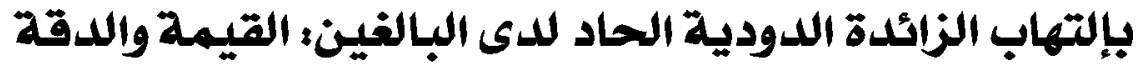

الهدف: تهدف هذه الدراسة إلى تصديد قيمة ودقة التصوير المقطعى متعدد الكواشف بإستخدام مواد التباين قبل إجراء العمليات الجراحية

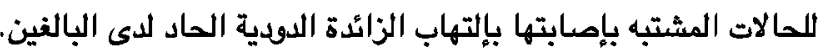

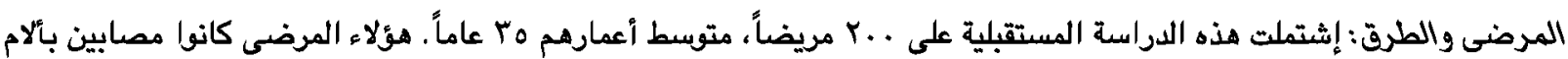

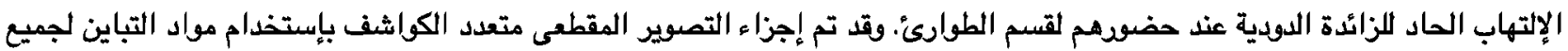

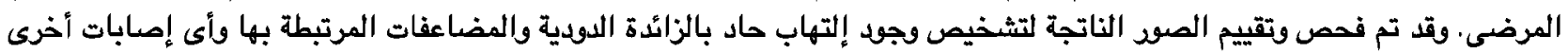
بالبطن أو الصوض.

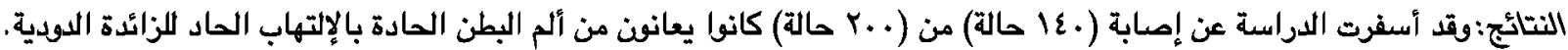

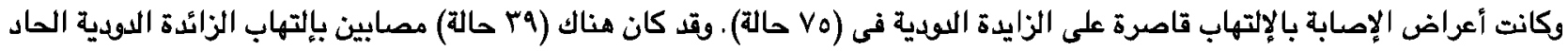

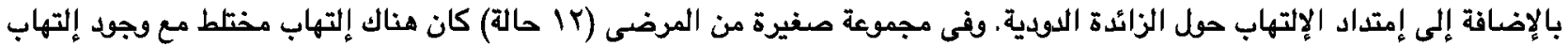

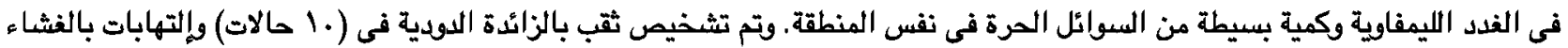

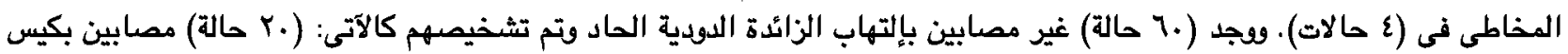

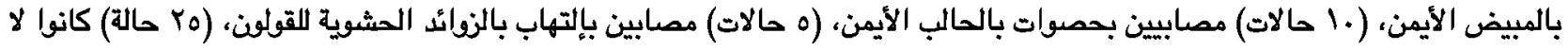

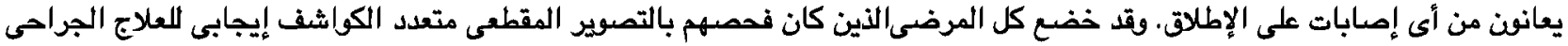

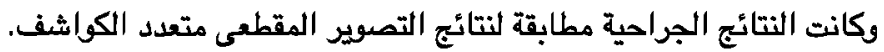

الإستتّاج: أثبت البحث أن التصوير المقطعى متعدد الكواشف بإستخدام مواد التباين طريقة دقيقة وفعالة لتشخيص إلتهاب الزائدة الدودية الحاد لدى البالغين. كما أنه يؤثر على خطة العلاج الجراحية وبالإضافة إلى ذلك فإنه يساعد فى تجنب إجراء الجراحات غير الضرئية. 